\section{Particle Bombardment of Apple Leaf Explants Influences Adventitious Shoot Formation}

\author{
P. Gercheva ${ }^{1,2,3}$, R.H. Zimmerman'2, L.D. Owens ${ }^{1}$, C. Berry ${ }^{1}$, and \\ F.A. Hammerschlag ${ }^{1,4}$ \\ U.S. Department of Agriculture, Agricultural Research Service, Plant Sciences \\ Institute, Beltsville, MD 20705-2350
}

Additional index words. Malus domestica, microprojectile, organogenesis, biolistics

\begin{abstract}
Shoot regeneration from apple (Malus domestica Borkh.) leaf explants following particle bombardment at various acceleration pressures was studied. Basal leaf segments of micropropagated 'Royal Gala' apple were bombarded with $1 \mu \mathrm{m}$ gold particles, accelerated using helium pressures of 4.5, 6.2, 7.6, 9.3, or $13.8 \mathrm{MPa}(650-2000 \mathrm{psi})$, and cultured on shoot regeneration medium consisting of N6 salts supplemented with $10 \mu_{\mathrm{M}}$ TDZ for 5, 10, or 20 days in darkness. Bombarded and control explants exhibited $63 \%$ to $100 \%$ shoot regeneration. With a 5-day dark period, average shoot production per explant ranged from 6.1 to 14; bombardments of 4.5 and 6.2 MPa significantly increased shoot production over the controls. With a 10-day dark period, average shoot production per explant ranged from 9.1 to 22 following bombardment at 9.3 and 6.2 MPa, respectively. Following bombardment at 6.2 MPa, 75\% of the explants produced more than 20 regenerants per explant. With a 20-day dark period, average shoot production per explant ranged from 8.9 to 19 following bombardment at 13.8 MPa and following no bombardment, respectively. Shoot production per explant was significantly less than the controls following bombardments ranging from 6.2 to 13.8 MPa. Shoot production was highest per explant with particle bombardment at 6.2 MPa followed by incubation in darkness for 10 days. Chemical name used: thidiazuron (TDZ).
\end{abstract}

Among deciduous fruit tree species, apple is an attractive candidate for gene transfer because of its economic importance (Dandekar et al., 1990, ), ability to regenerate easily from somatic tissues (Belaizi et al., 1991; Fasolo et al., 1989; James et al., 1988; Korban et al., 1992; Welander, 1988), long juvenile period, high level of self-incompatibility, and high heterozygosity (Brown, 1975). Agrobacteriummediated transformation studies in several laboratories have succeeded in producing transgenic apple plants; however, the transformation frequencies (based on the number of transformants divided by the number of nontransformed regenerants) have been low (i.e., $0.2 \%$ to $0.8 \%$ ) (James et al., 1989; Maheswaran et al., 1992). In James et al.'s (1989) and Maheswaran et al.'s (1992) studies, because regeneration frequencies were high $(80 \%$ to $100 \%$ explant regeneration with

Received for publication 23 Mar. 1994. Accepted for publication 17 Aug. 1994. Mention of a trademark, proprietary product, or vendor by the U.S. Dept. of Agriculture does not imply its approval to the exclusion of other products or vendors that also may be suitable. We gratefully acknowledge William Potts for help with statistical analyses. The cost of publishing this paper was defrayed in part by the payment of page charges. Under postal regulations, this paper therefore must be hereby marked advertisement solely to indicate this fact.

${ }^{1}$ Plant Molecular Biology Laboratory.

${ }^{2}$ Fruit Laboratory.

${ }^{3}$ Current address: Fruit Growing Institute, Ostromila 12, 4004 Plovdiv, Bulgaria.

${ }^{4}$ To whom reprint requests should be addressed. five to 10 regenerants per explant), low frequencies of transformation could have been due to a low frequency of Agrobacterium infection. In addition to particle bombardment being effective for direct DNA delivery into plant cells and the production of stable transformants (Christou et al., 1991; Fromm et al., 1990; Gordon-Kamm et al., 1990; McCabe et al., 1988), it also has been used to improve the efficiency of Agrobacterium-mediated transformation by increasing the number of wound sites that are able to support Agrobacterium infection and DNA transfer into plant cells (Bidney et al., 1992). However, microprojectile-induced wounding and associated physical and biochemical events can decrease the regeneration capacity of target tissues (Perl et al., 1992; Vain et al., 1993). In our study, we report on optimizing conditions for bombarding apple leaf explants and subsequently regenerating adventitious shoots from bombarded explants.

\section{Materials and Methods}

Plant material. Leaf material used in all experiments was taken from in vitro-cultured axillary shoots of 'Royal Gala' apple. Donor cultures were maintained by transferring 1 - to 2-cm-long axillary shoots at 20-day intervals onto multiplication medium consisting of MS salts (Murashige and Skoog, 1962) supplemented with $0.56 \mathrm{~mm}$ myo-inositol, $1.2 \mu \mathrm{M}$ thiamine $\mathrm{HCl}, 4.4 \mu \mathrm{M} \mathrm{N}$-(phenylmethyl)- $1 \mathrm{H}$ purin-6-amine (BA), $0.5 \mu \mathrm{M} 1 H$-indole-3butanoic acid (IBA), $1.3 \mu \mathrm{M}$ gibberellic acid $\left(\mathrm{GA}_{3}\right), 87.6 \mathrm{~mm}$ sucrose, and $7 \mathrm{~g}$ Difco Bacto- agar/liter. The $\mathrm{pH}$ was adjusted to 5.6 before autoclaving at $121 \mathrm{C}$ and $98 \mathrm{KPa}$ for $15 \mathrm{~min}$. Shoot cultures were incubated at 26C with a 16-h photoperiod provided by cool-white fluorescent tubes at $40 \mu \mathrm{mol} \cdot \mathrm{m}^{-2} \cdot \mathrm{s}^{-1}$.

Preparation of target tissues. The two youngest, fully expanded leaves of 15-day-old in vitro-cultured axillary shoots were excised and stored in petri dishes on sterile filter paper moistened with deionized distilled water. The basal one-third of each leaf (with petiole) was dissected and placed abaxial side up on regeneration medium. Eight to 10 explants were placed in the central 2 -cm zone of each $1 \times 9$ $\mathrm{cm}$ petri dish.

Particle bombardment. The biolistic particle delivery system (model PDS-1000/He; E.I. du Pont de Nemours and Co., Wilmington, Del.) was used to deliver gold particles (BioRad, Melville, N.Y.). For all experiments, the distance between the rupture disk and the macrocarrier was set at $6 \mathrm{~mm}$, the macrocarrier flight distance at $1 \mathrm{~cm}$, and microcarrier flight distance at $9 \mathrm{~cm}$.

Gold particles ( $1 \mu \mathrm{m}$ in diameter, $60 \mathrm{mg}$ ) were suspended in $1 \mathrm{ml}$ of $95 \%$ ethanol, sonicated for $30 \mathrm{sec}$ and centrifuged at 16,000 $\times g$ for $10 \mathrm{sec}$. After two additional centrifugations in sterile, deionized distilled water, the particles were stored in 1.5-ml microcentrifuge tubes at $-20 \mathrm{C}$ until needed.

Immediately before bombardment, the sample chamber and associated parts were sterilized with $70 \%$ ethanol and air-dried under sterile conditions. Macrocarriers were loaded with $7 \mu \mathrm{l}$ of sonicated, gold particle suspension and air-dried. Rupture disks were dipped in isopropanol before use to prevent delamination and gas leakage. Bombardments were conducted with the helium pressure adjusted to 4.5, 6.2, 7.6, 9.3, or 13.8 MPa. Nontreated leaves $(0 \mathrm{MPa})$ served as controls.

Plant regeneration. Immediately after the bombardments, petri dishes were incubated in darkness at 26C. The regeneration medium (Fasolo et al., 1989) consisted of N6 macrosalts (Chu et al., 1975), LS microsalts (Linsmaier and Skoog, 1965), 0.56 mм myo-inositol, $3 \mu \mathrm{M}$ thiamine $\mathrm{HCl}, 87.6 \mathrm{~mm}$ sucrose, and $300 \mathrm{mg}$ casein hydrolysate and $7 \mathrm{~g}$ Difco-Bacto agar/ liter. The medium was adjusted to $\mathrm{pH} 5.2$ before autoclaving. Three periods of dark incubation $(5,10$, and 20 days) were used for each level of helium pressure. Explants were subcultured every 20 days. The number of adventitious shoots was estimated following each of the three dark periods, 30 days on regeneration medium (16-h photoperiod), and 10 days on MS medium for shoot elongation. Each treatment was replicated three times, with a minimum of eight leaves per pressure per dark treatment per replication.

Statistical analysis. The six pressure levels $(0.0,4.5,6.2,7.6,9.3$, and 13.8 MPa $)$ and three dark periods $(5,10$, and 20 days) were arranged in a complete-block design. The number of shoots per explant was approximated because of the difficulty of directly counting shoots. For each replication, the relative frequency of explants with shoot counts in the four categories $(0,1$ to 10,11 to 20 , and >20) 
was recorded. The number of shoots per explant was estimated by assuming that the mean shoot counts for the four categories were 0 , $5.5,15.5$, and 25.5 , respectively. A linear means model was fitted to the approximate shoot counts using the SAS general linear model procedure (SAS Institute, 1989). Within each darkness duration, the means for each pressure were compared to the zero pressure treatment. In addition, linear and quadratic polynomial contrasts were tested across the three darkness durations for each pressure treatment.

\section{Results}

In general, particle bombardment had little effect on percentage of adventitious shoot formation. With most bombardment pressure treatments, $80 \%$ to $100 \%$ of the explants regenerated at least one shoot per explant (Table 1). However, particle bombardment and number of days of darkness significantly influenced the number of shoots produced per leaf explant (Table 2).

With 5 days of darkness and no bombardment, average shoot production per explant was $<10$, with only $3 \%$ of the explants producing more than 20 shoots per explant. Only after 4.5- and 6.2-MPa bombardments was the average number of shoots produced per explant significantly higher than that of the controls, with $\approx 25 \%$ of the explants producing $>20$ shoots per explant. By increasing the days in darkness to 10 , the average number of shoots produced per explant increased significantly

Table 1. The effect of particle bombardment and days of dark incubation on the percentage of explants that regenerated shoots from 'Royal Gala' apple leaf explants. ${ }^{2}$

\begin{tabular}{lcrr}
\hline \hline & \multicolumn{3}{c}{ Regeneration (\%) } \\
\cline { 2 - 4 } Pressure & \multicolumn{3}{c}{ Dark period (days) } \\
\cline { 2 - 4 }$(\mathrm{MPa})$ & \multicolumn{1}{c}{5} & \multicolumn{1}{c}{10} & 20 \\
\hline 0 & $63 \pm 9.3$ & $94 \pm 4.4$ & $97 \pm 4.1$ \\
4.5 & $96 \pm 5.1$ & $83 \pm 7.3$ & $93 \pm 5.1$ \\
6.2 & $82 \pm 8.0$ & $94 \pm 5.4$ & $80 \pm 7.8$ \\
7.6 & $84 \pm 7.2$ & $94 \pm 4.8$ & $94 \pm 4.5$ \\
9.3 & $80 \pm 7.8$ & $94 \pm 4.5$ & $100 \pm 5.4$ \\
13.8 & $63 \pm 9.9$ & $87 \pm 6.6$ & $96 \pm 4.4$ \\
\hline
\end{tabular}

${ }^{2}$ Values represent the average of three replications, with a minimum of eight explants per pressure per dark period treatment per replication. at $0.0,6.2$, and $13.8 \mathrm{MPa}$ and was more than 10 at all pressure treatments, except for $9.3 \mathrm{MPa}$.

With 10 days of darkness and no bombardment, average shoot production per explant was 17 , with $49 \%$ of the explants producing $>20$ shoots per explant. Following particle bombardments at $6.2 \mathrm{MPa}$, the average number of shoots produced per explant was 22 , with $75 \%$ of the explants producing $>20$ shoots per explant. Only at $9.3 \mathrm{MPa}$ was there a significant reduction in the average number of shoots produced per explant compared to the control, with only $7 \%$ of the explants producing $>20$ shoots per explant. Although at 7.6 and $13.8 \mathrm{MPa}$, the average number of shoots produced per explant was not significantly different from the control, only $17 \%$ of the explants produced $>20$ shoots per explant.

With 20 days of darkness and no bombardment, average shoot production per explant was 19 , with $50 \%$ of the explants producing $>20$ shoots per explant. A significant decrease in the number of shoots produced per explant compared to the controls occurred following particle bombardments ranging from 6.2 to 13.8 MPa.

Linear and quadratic polynomial contrasts suggested that 10 days of darkness was optimal. Particle bombardment at 6.2 MPa followed by 10 days of darkness ranked highest for generating the most shoots per leaf explant.

\section{Discussion}

Because plant regeneration is often a limiting factor in producing transgenic plants and particle bombardment can have a negative impact on plant regeneration (Perl et al., 1992; Taylor and Vasil, 1991; Vasil et al., 1991), our study focused on the effects of particle bombardment on the frequency of shoot regeneration from apple explants.

Several factors, such as composition of the regeneration medium, type of explant, leaf position on the mother plant, light intensity, and genotype are known to affect apple regeneration (Fasolo et al., 1989; Korban et al., 1992). 'Royal Gala' was chosen for these experiments because of its high regeneration capacity and because of the culture medium and conditions that were described previously (Fasolo et al., 1989). Bombardment with high velocity microprojectiles was found to posi-

Table 2. The effect of particle bombardment and days of dark incubation on average number of 'Royal Gala' apple shoots regenerated per leaf explant.

\begin{tabular}{|c|c|c|c|c|c|c|c|c|}
\hline \multirow{3}{*}{$\begin{array}{l}\text { Pressure } \\
(\mathrm{MPa})\end{array}$} & \multicolumn{6}{|c|}{ Shoots per explant } & \multirow{2}{*}{\multicolumn{2}{|c|}{ Contrasts $^{2}$}} \\
\hline & \multicolumn{6}{|c|}{ Dark period (days) } & & \\
\hline & & 5 & & 10 & & 20 & $\mathrm{~L}$ & $\mathrm{Q}$ \\
\hline 0 & 6.1 & $(37,40,20,3)^{y}$ & 17.0 & $(6,24,20,49)$ & 19.0 & $(3,6,41,50)$ & 0.000 & 0.003 \\
\hline 4.5 & $14.0^{* * *}$ & $(3,43,29,24)$ & 17.0 & $(17,10,23,50)$ & 15.0 & $(7,22,47,24)$ & 0.795 & 0.154 \\
\hline 6.2 & $11.0^{*}$ & $(19,37,19,26)$ & 22.0 & $(5,5,15,75)$ & $13.0^{*}$ & $(20,13,43,23)$ & 0.648 & 0.000 \\
\hline 7.6 & 7.9 & $(17,60,13,10)$ & 13.0 & $(7,33,43,17)$ & $10.0^{* *}$ & $(7,48,39,7)$ & 0.773 & 0.123 \\
\hline 9.3 & 8.4 & $(20,40,40,0)$ & $9.1^{* *}$ & $(7,60,27,7)$ & $11.0^{* *}$ & $(0,58,37,6)$ & 0.477 & 0.896 \\
\hline 13.8 & 7.5 & $(38,31,18,13)$ & 14.0 & $(13,13,57,17)$ & $8.9^{* * *}$ & $(4,64,29,4)$ & 0.826 & 0.044 \\
\hline
\end{tabular}

${ }^{2} \mathrm{~L}=$ linear, $\mathrm{Q}=$ quadratic; $P$ values corresponding to $\mathrm{L}$ and $\mathrm{Q}$ polynomial contrasts across the three darkness durations.

${ }^{y}$ Numbers in parentheses represent percentages of explants with 0,1 to 10,11 to 20 , and $>20$ adventitious shoots per explant.

*,**,***Significant difference from the corresponding zero pressure average at $P \leq 0.05,0.01$, or 0.001 , respectively.

tively and negatively influence the ability of 'Royal Gala' apple leaf tissues to regenerate shoots. A significant helium pressure (particle velocity) $\times$ duration of postbombardment dark period interaction was observed. Particle bombardment at low velocities combined with 5 days of dark culture resulted in an increase of the regeneration response from leaf explants compared to the controls. This increase may be due to the creation of wound sites from which plants can regenerate (Sriskandarajah et al., 1990), whereas high-velocity bombardment may have damaged the cells.

In general, particles accelerated at a low helium pressure $(4.5$ or $6.2 \mathrm{MPa})$ did not adversely affect the number of regenerants per leaf explant, and when particle bombardment at 4.5 or $6.2 \mathrm{MPa}$ was combined with 10 days of darkness, the frequency of regeneration per leaf explant was generally higher than with 5 or 20 days of dark culture. Other studies also have demonstrated that the length of the dark period influences regeneration from apple leaf explants (Dufour, 1990; Fasolo et al., 1989; Korban et al., 1992).

Bombardments at higher pressures (7.6, $9.3,13.8 \mathrm{MPa}$ ) followed by 10 or 20 days of darkness caused a decrease in the number of regenerants per explant. These results indicate that a helium pressure of $7.6 \mathrm{MPa}$, commonly recommended for use in plant systems (Kikkert, 1993), may be too high for apple leaf tissues. The adverse effects of high-velocity bombardment may be due to wound-induced ethylene production or the release of proteolytic enzymes from injured cells. If so, tissue treatments that decrease ethylene synthesis or action and minimize cell membrane damage likely would improve morphogenic potential (Perl et al., 1992).

These experiments demonstrate that leaf explants of 'Royal Gala' apple have a high regeneration frequency following bombardment under optimized conditions and, therefore, can be recommended for transformation studies. Based on these results, we recommend particle bombardment at $6.2 \mathrm{MPa}$ combined with 10 days of dark incubation for future transformation studies with apple leaves.

\section{Literature Cited}

Belaizi, M.,H.Paul, R.S. Sangwa, and B.S. SangwanNorreel. 1991. Direct organogenesis from internodal segments of in vitro grown shoots of apple cv. Golden Delicious. Plant Cell Rpt. 9:471474.

Bidney, D., Ch. Scelonge, J. Martich, M. Burrus, L. Sims, and G. Huffman. 1992. Microprojectile bombardment of plant tissues increases transformation frequency by Agrobacterium tumefaciens. Plant Mol. Biol. 18:301-313.

Brown, A.G. 1975. Apples, p. 3-37. In: J. Janick and J.N. Moore (eds.). Advances in fruit breeding. Purdue Univ. Press, W. Lafayette, Ind.

Christou, P., T. Ford, and M. Kofron. 1991. Production of transgenic rice (Oryza sativa L.) plants from agronomically important indica and japonica varieties via electric discharge particle acceleration of exogenous DNA into immature zygotic embryos. Bio/Technology 9:957-962.

Chu, C.C., C.C. Wang, C.S. Sun, C. Hsu, K.C. Yin, C.Y. Chu, and F.Y. Pi. 1975. Establishment of 
an efficient medium for anther culture of rice through comparative experiments on the nitrogen sources. Sci. Sinica 18:659-688.

Dandekar, A.M., S.L. Uratsu, and N. Matsuta. 1990 Factors influencing virulence in Agrobacteriummediated transformation of apple. Acta Hort. 280:483-494.

Dufour, M. 1990. Improving of yield of adventitious shoots in apple. Acta Hort. 280:51-60.

Fasolo, F., R.H. Zimmerman, and I. Fordham. 1989. Adventitious shoot formation on excised leaves of in vitro grown shoots of apple cultivars. Plant Cell Tissue Organ Cult. 16:75-87.

Fromm, M., F. Morrish, C. Armstrong, R. Williams, J. Thomas, and T. Klein. 1990. Inheritance and expression of chimeric genes in the progeny of transgenic maize plants. Bio/Technology 8:833844.

Gordon-Kamm, W.J., T.M. Spencer, M.L. Mangano, T.R. Adams, R.J. Daines, W.G. Start, J.V. O'Brien, S.A. Chambers, W.R. Adams, N.W. Willetts, T.R. Rice, C.J.MacKay, R.W. Krueger, A.P. Kansch, and P.G. Lemaux. 1990. Transformation of maize cells and regeneration of fertile transgenic plants. Plant Cell 2:603-618.

James, D.J., A.J. Passey, and E. Rugini. 1988. Factors affecting high frequency plant regeneration from apple leaf tissues cultured in vitro. J. Plant Physiol. 132:148-154.

James, D.J., A.J. Passey, D.J. Barbara, and M.
Bevan. 1989. Genetic transformation of apple (Malus pumula Mill.) using a disarmed Ti-binary vector. Plant Cell Rpt. 7:658-661.

Kikkert, J.R. 1993. The Biolistic PDS-1000/He device. Plant Cell Tissue Organ Cult. 33:221226.

Korban, S.S. and H. Chen. 1992. Apple, p. 203-227. In: F.A. Hammerschlag and R.E. Litz (eds.). Biotechnology of perennial fruit crops. C.A.B. International, Wallingford, England.

Korban, S.S., P.A. O'Connor, and A. Elobeidy. 1992. Effects of thidiazuron, naphthaleneacetic acid, dark incubation and genotype on shoot organogenesis from Malus leaves. J. Hort. Sci. 67:341-349.

Linsmaier, E.M. and F. Skoog. 1965. Organic growth factor requirements of tobacco tissue cultures. Physiol. Plant. 18:100-127.

Maheswaran, G., M. Welander, J.F. Hutchinson, M.W. Graham, and D. Richards. 1992. Transformation of apple rootstock M26 with Agrobacterium tumefaciens. J. Plant Physiol. 139:560-568

McCabe, D., W. Swain, B. Martinell, and P. Christou. 1988. Stable transformation of soybean (Glycine $\max$ ) by particle acceleration. Bio/Technology 6:923-926.

Murashige, T. and F. Skoog. 1962. A revised medium for rapid growth and bioassays with tobacco tissue cultures. Physiol. Plant. 15:473-497.
Perl, A., H. Kless, A. Blumenthal, G. Galili, and E. Galun. 1992. Improvement of plant regeneration and GUS expression in scutellar wheat calli by optimization of culture conditions and DNAmicroprojectile delivery procedures. Mol. Gen. Genet. 235:279-284.

SAS Institute. 1989. SAS/STAT user's guide. 4th ed. Version 6. SAS Institute, Cary, N.C.

Sriskandarajah, S., R.M. Skirvin, H. Abu-Qaoud, and S.S. Korban. 1990. Factors involved in shoot elongation and growth of adventitious and axillary shoots of three apple scion cultivars in vitro. J. Hort. Sci. 65:113-121.

Taylor, M.G. and I.K. Vasil. 1991. Histology of, and physical factors affecting, GUS expression in pearl millet (Pennisetum glauca (L.) R.Br.) embryos following microprojectile bombardment. Plant Cell Rpt. 10:120-125.

Vain, P., M. McMullen, and J. Finer. 1993. Osmotic treatment enhances particle bombardment mediated transient and stable transformation of maize. Plant Cell Rpt. 12:84-88.

Vasil, V., S.M. Brown, D. Re, M.E. Fromm, and I.K. Vasil. 1991. Stably transformed callus lines from microprojectile bombardment of cell suspension cultures of wheat. Bio/Technology 9:743-747.

Welander, M. 1988. Plant regeneration from leaf and stem segments of shoots raised in vitro from mature apple trees. J. Plant Physiol. 132:738-744. 